\title{
Stimulus specific activity patterns in the granule cell networks of
} mice

\section{Vikrant Kapoor* and Nathaniel Urban}

Address: Department of Biological Sciences and Center for Neural Basis of Cognition, Carnegie Mellon University, Pittsburgh, PA 15213, USA

Email: Vikrant Kapoor* - vikrantk@andrew.cmu.edu

* Corresponding author

from Sixteenth Annual Computational Neuroscience Meeting: CNS*2007

Toronto, Canada. 7-12 July 2007

Published: 6 July 2007

BMC Neuroscience 2007, 8(Suppl 2):PI73 doi:I0.I I86/I47I-2202-8-S2-PI73

(c) 2007 Kapoor and Urban; licensee BioMed Central Ltd.

It has been speculated that the olfactory bulb encodes information in the form of stimulus specific activity patterns. One of the key features of this population activity is the emergence of odor-specific spatial patterns of mitral cell spiking over a time course of 200-800 ms following stimulus (-odor) onset. We are interested in understanding the mechanisms involved in establishing and maintaining these spatial patterns. Here, we investigated the temporal response characteristics of granule cell activity by imaging activity in populations of olfactory bulb cells following bulk loading of calcium dye in olfactory bulb slices. We found that granule cells show varied (ranging from 0-900 ms) but reliable activation latencies (std. dev. $=50 \mathrm{~ms}$ ). Moreover, we found that these activity patterns played a significant role in the generation and the maintenance of reliable spike patterns in mitral cells. Experiments in which multiple glomeruli were stimulated showed that the latency of granule cell activity is input specific and that individual granule cells respond most reliably to specific temporal patterns of stimulation. These data suggest that glomerular ( stimulus) identity is encoded in the form of latencies of granule cells activity, which in turn results in distinct stimulus specific changes in the pattern of mitral cell activity. 